\title{
Use of Cough Peak Flow Measured by a Ventilator to Predict Re-Intubation When a Spirometer Is Unavailable
}

\author{
Linfu Bai MD and Jun Duan MD
}

\begin{abstract}
BACKGROUND: A ventilator includes the function to measure flow velocity. We aimed to compare the predictive accuracy for re-intubation diagnosed by cough peak flow (CPF) measured by a spirometer and a ventilator. METHODS: Endotracheally intubated subjects who passed a spontaneous breathing trial were enrolled. Before extubation, CPF was measured by a spirometer and a ventilator, respectively. Re-intubation was recorded at $72 \mathrm{~h}$ after extubation. RESULTS: A total of 126 subjects were enrolled. Among them, 15 subjects (12\%) experienced re-intubation. CPF was lower in re-intubated subjects than those without re-intubation (measured by a spirometer: $54 \pm 30 \mathrm{~L} / \mathrm{min}$ vs $86 \pm 37 \mathrm{~L} / \mathrm{min}, P<.001$; and measured by a ventilator: $50 \pm 22 \mathrm{~L} / \mathrm{min}$ vs $80 \pm 26 \mathrm{~L} / \mathrm{min}$, $P<.001)$. CPF measured by a spirometer and a ventilator had similar area under the curve of receiver operating characteristic $(0.79$ vs $0.83, P=.26)$. When a $\mathrm{CPF}$ of $56.4 \mathrm{~L} / \mathrm{min}$ was measured by a spirometer as cutoff value, the sensitivity and specificity to distinguish re-intubation was $\mathbf{7 3}$ and $87 \%$, respectively. When it was measured by a ventilator, the cutoff value, sensitivity, and specificity were $56 \mathrm{~L} / \mathrm{min}, 73 \%$, and $85 \%$, respectively. CONCLUSIONS: CPF measurement by a ventilator was convenient, affordable, and safe. It had a predictive accuracy for re-intubation similar to that of a spirometer. Key words: cough peak flow; spontaneous breathing trial; extubation; re-intubation. [Respir Care 2017;62(5):566-571. ( 2017 Daedalus Enterprises]
\end{abstract}

\section{Introduction}

Extubation is recommended when a patient passes a spontaneous breathing trial (SBT). ${ }^{1-3}$ However, re-intubation frequently happens in ICUs. The prevalence of reintubation within $48-72 \mathrm{~h}$ after planned extubation is 9-17\% (average value of 13\%).4-7 In addition, re-intubation is associated with an 8 -fold increase in nosocomial pneumonia and a 3 -fold increase in hospital death. ${ }^{8}$ Thus, it is very important to decrease re-intubation. The first step is to identify patients at high risk for re-intubation.

Cough strength is strongly associated with re-intubation; patients with a weak cough are more likely to expe-

The authors are affiliated with the Department of Respiratory Medicine, First Affiliated Hospital of Chongqing Medical University, Chongqing, China.

Correspondence: Jun Duan MD, Department of Respiratory Medicine, First Affiliated Hospital of Chongqing Medical University, Youyi Road 1, Yuzhong District, Chongqing 400016, China. E-mail: duanjun412589@163.com.

DOI: $10.4187 /$ respcare. 05260 rience re-intubation. ${ }^{5,9-20}$ Cough peak flow (CPF) is commonly used to reflect cough strength because it is an objective measurement. A flow meter is the most common device to measure CPF. However, not all ICUs provide a flow meter to measure CPF; some of them use a semiquantitative cough strength assessment..$^{59-13}$ However, a semiquantitative assessment is not as accurate as an objective assessment. Thus, a device existing in all ICUs serving as an objective measurement of cough strength is needed.

Invasive mechanical ventilators exist in all ICUs. The ventilator itself includes an internal flow meter that can objectively measure CPF. Thus, we aimed to explore whether the predictive accuracy of re-intubation diagnosed by cough peak flow measured by a ventilator was the same as that of a spirometer.

\section{Methods}

This was a prospective observational study performed in a respiratory ICU of a teaching hospital from September 2014 to July 2016. Endotracheally intubated patients with 
a successful SBT were eligible for this study. However, patients with age $<18$ years and inability to cough on command were excluded. We also excluded patients who had undergone tracheotomy. Informed consent was obtained from the subjects or their families. The ethics committee and institutional review board of the First Affiliated Hospital of Chongqing Medical University approved this study.

Subjects were managed per our hospital's protocol. Strategies to prevent ventilator-associated pneumonia (eg, elevation of the head of the bed) were used in all subjects. Antibiotics were administered according to the results of culture and the attending physicians' experience in patients with pneumonia. Anticoagulant therapy and thrombolytic therapy were used in subjects with pulmonary embolism. Bronchodilators were used in subjects with asthma or bronchospasm. Mucus-controlling agents were used in subjects with excessive viscous mucus secretions. Adjustment of parameters and liberation from mechanical ventilation were mainly managed by attending physicians and respiratory therapists. Every morning, the sedation was interrupted to judge whether subjects required sedation again or had reached the criteria for a weaning test.

Criteria for the weaning test were as follows: improvement of the underlying cause of acute respiratory failure, $\mathrm{P}_{\mathrm{aO}_{2}} \geq 60 \mathrm{~mm} \mathrm{Hg}$ with $\mathrm{F}_{\mathrm{IO}_{2}} \leq 0.5$, PEEP $\leq 5 \mathrm{~cm} \mathrm{H}_{2} \mathrm{O}$, temperature $\leq 38^{\circ} \mathrm{C}$, systolic blood pressure between 90 and $180 \mathrm{~mm} \mathrm{Hg}$ (without vasopressor therapy or with only a low-dose vasopressor, such as dopamine or dobutamine $\leq 5 \mu \mathrm{g} / \mathrm{kg} / \mathrm{min}$ ), heart rate $\leq 140$ beats $/ \mathrm{min}$, and breathing frequency $\leq 30$ breaths $/ \mathrm{min} .{ }^{15}$ If the criteria for the weaning test were reached, we performed an SBT for $120 \mathrm{~min}$. Low-level pressure support was used for an SBT $\left(6 \mathrm{~cm} \mathrm{H}_{2} \mathrm{O}\right.$ for an inner diameter of the endotracheal tube $\geq 7.5 \mathrm{~mm}$ and $8 \mathrm{~cm} \mathrm{H}_{2} \mathrm{O}$ for $<7.5 \mathrm{~mm}$ ). However, subjects who presented with one of the following criteria were defined as SBT failure: breathing frequency $\geq 35$ breaths/min, frequency/tidal volume (rapid shallow breathing index) $>105$, $\mathrm{S}_{\mathrm{pO}_{2}}<90 \%$ at $\mathrm{F}_{\mathrm{IO}_{2}} \geq 0.5$, heart rate $\geq 140$ or $\leq 50$ beats $/ \mathrm{min}$, systolic blood pressure $\geq 180$ or $\leq 90 \mathrm{~mm} \mathrm{Hg}$, acute re-

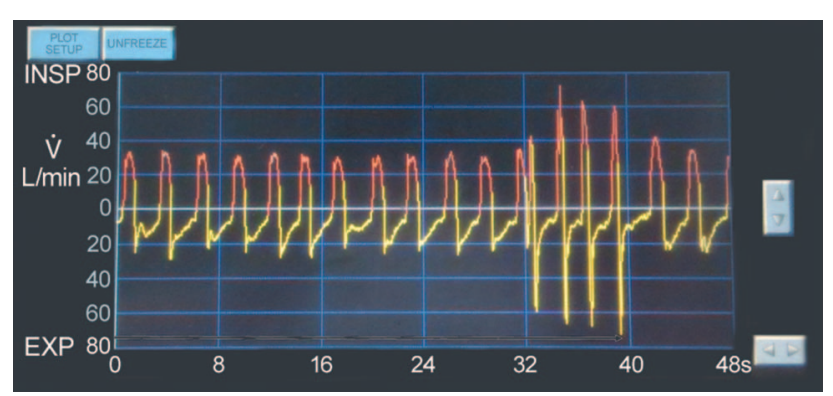

Fig. 1. Ventilator screenshot of cough peak flow when a subject was coached to cough.

\section{QUICK LOOK}

\section{Current knowledge}

Cough peak flow is a strong predictor of re-intubation when a patient successfully completes a spontaneous breathing trial. A flow meter is commonly used to measure cough peak flow, but not all ICUs provide a flow meter to measure cough peak flow.

\section{What this paper contributes to our knowledge}

Cough peak flow measured by a ventilator was positively associated with re-intubation. The predictive accuracy of re-intubation was similar when cough peak flow was measured by a ventilator compared with when it was measured by a spirometer.

spiratory acidosis with increasing in $\mathrm{P}_{\mathrm{aCO}_{2}} \geq 10 \mathrm{~mm} \mathrm{Hg}$, diminishing consciousness or diaphoresis, and clinical signs indicating respiratory muscle fatigue, labored breathing, or both. 15

When a subject successfully completed an SBT, we collected demographics such as age, sex, diagnosis, and physiological variables. Before removal of the endotracheal tube, we measured CPF. Before measurement, the head of the bed was elevated at $30-45^{\circ}$, and secretions were removed by suction. First, we measured CPF using the internal flow meter of the ventilator. (PB840, Covidien, Mansfield, Massachusetts). The parameters of the ventilator were the same as those in an SBT. We coached the subject to cough with as much effort as possible. At the same time, we froze the waveform of the flow velocity. Then we visually picked the peak of the flow velocity from the graph and kept the number to single digits (Fig. 1). We repeated the measurements 3 times. The best of 3 values was recorded. After measurements, subjects were ventilated with comfortable settings for $5 \mathrm{~min}$ as the washout time. Finally, we measured CPF using a spirometer (Chestgraph HI-101, Chest MI, Tokyo, Japan). We disconnected the ventilator, connected the spirometer to the endotracheal tube, and coached the subject to cough with as much effort as possible. We again recorded the best of 3 values.

After extubation, subjects were followed up to discharge or death in hospital. The re-intubation was recorded at $72 \mathrm{~h}$ after extubation. Re-intubation criteria were as follows: respiratory or cardiac arrest, inability to correct dyspnea, failure to maintain $\mathrm{P}_{\mathrm{aO}}>60 \mathrm{~mm} \mathrm{Hg}$ with supplemental oxygen $>10 \mathrm{~L} / \mathrm{min}$, hemodynamic instability without response to fluids and vasoactive agents, and development of conditions necessitating intubation to protect the airway (coma or seizure disorders) or to manage copious tracheal secretions. 
Statistical analysis was performed with MedCalc (Ostend, Belgium). An unpaired Student $t$ test was used to analyze normally distributed continuous variables, a MannWhitney U test was used to analyze non-normally distributed continuous variables, and the chi-square or Fisher exact test was used to analyze categorical variables. The difference between CPF measured by a spirometer and that measured by a ventilator was analyzed using a paired Student $t$ test. The ability to predict re-intubation diagnosed by $\mathrm{CPF}$ was determined using the area under the curve of receiver operating characteristic. The Hanley and McNeil method was used to compare the predictive accu-

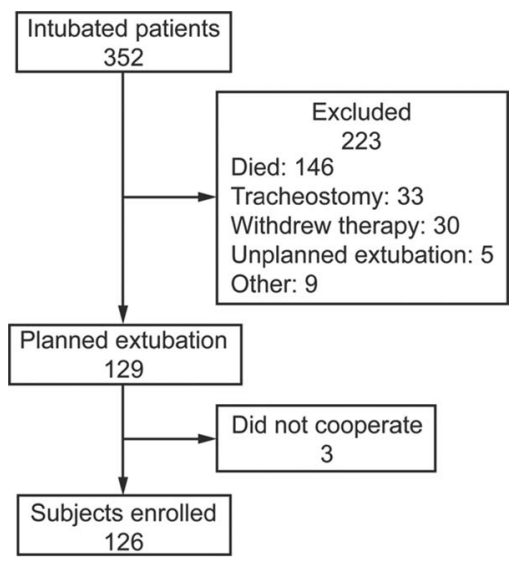

racy of re-intubation diagnosed by $\mathrm{CPF}$ measured by a spirometer and a ventilator. ${ }^{21}$ A $P$ value of $<.05$ was considered to indicate statistical significance.

\section{Results}

A total of 126 subjects were enrolled in this study (Fig. 2). Among them, 15 subjects (12\%) experienced re-intubation within $72 \mathrm{~h}$ after extubation (Table 1). There were no differences in sex, diagnosis, physiological variables, and arterial blood gas tests before extubation between subjects with and without re-intubation. However, subjects who were re-intubated were older and had longer intubation periods before extubation than those who underwent a successful extubation. They also had lower CPF than successfully extubated subjects, whether the CPF was measured by a spirometer or a ventilator. Further, re-intubated subjects had higher hospital mortality (Table 2).

CPF measured by a spirometer was slightly higher than that measured by a ventilator $(82 \pm 38 \mathrm{~L} / \mathrm{min}$ vs $77 \pm 27 \mathrm{~L} / \mathrm{min}$, $P=.008)$. However, there was a positive correlation between CPF measured by a ventilator and a spirometer (Fig. $3)$. The optimal cutoff value, sensitivity, specificity, positive predictive value, negative predictive value, positive likelihood ratio, and negative likelihood ratio were summarized in Table 3. The area under the curve of receiver

Fig. 2. Flow chart.

Table 1. Data Collected Just Before Extubation Between Subjects With and Without Re-Intubation

\begin{tabular}{|c|c|c|c|}
\hline Characteristics & Re-Intubation $(n=15,12 \%)$ & No Re-Intubation $(n=111,88 \%)$ & $P$ \\
\hline Age, mean \pm SD y & $77 \pm 13$ & $66 \pm 14$ & .006 \\
\hline Female sex, $\%$ & 13 & 22 & .52 \\
\hline \multicolumn{4}{|l|}{ Diagnosis, $n(\%)$} \\
\hline COPD exacerbation & $4(27)$ & $48(43)$ & .27 \\
\hline Pneumonia & $5(33)$ & $26(23)$ & .52 \\
\hline ARDS & $4(27)$ & $13(12)$ & .12 \\
\hline Asthma & $0(0)$ & $3(3)$ & $>.99$ \\
\hline Pulmonary embolism & $1(7)$ & $4(4)$ & .46 \\
\hline Pulmonary cancer & $1(7)$ & $4(4)$ & .46 \\
\hline Others & $0(0)$ & $13(12)$ & .36 \\
\hline Breathing frequency, mean \pm SD breaths/min & $24 \pm 8$ & $21 \pm 6$ & .13 \\
\hline Rapid shallow breathing index, mean $\pm \mathrm{SD}$ breaths $/ \mathrm{min} / \mathrm{L}$ & $62 \pm 31$ & $48 \pm 24$ & .053 \\
\hline Heart rate, mean $\pm \mathrm{SD}$ beats $/ \mathrm{min}$ & $98 \pm 12$ & $96 \pm 17$ & .73 \\
\hline Systolic blood pressure, mean \pm SD mm Hg & $126 \pm 19$ & $132 \pm 20$ & .23 \\
\hline Diastolic blood pressure, mean $\pm \mathrm{SD} \mathrm{mm} \mathrm{Hg}$ & $71 \pm 8$ & $74 \pm 12$ & .30 \\
\hline Intubation periods, mean $\pm \mathrm{SD} \mathrm{d}$ & $9.3 \pm 4.4$ & $4.9 \pm 4.1$ & $<.001$ \\
\hline \multicolumn{4}{|l|}{ Arterial blood gas tests, mean $\pm \mathrm{SD}$} \\
\hline $\mathrm{pH}$ & $7.44 \pm 0.03$ & $7.43 \pm 0.06$ & .47 \\
\hline $\mathrm{P}_{\mathrm{aCO}_{2}}, \mathrm{~mm} \mathrm{Hg}$ & $44 \pm 9$ & $47 \pm 12$ & .49 \\
\hline $\mathrm{P}_{\mathrm{aO}_{2}} / \mathrm{F}_{\mathrm{IO}_{2}}, \mathrm{~mm} \mathrm{Hg}$ & $281 \pm 108$ & $248 \pm 83$ & .16 \\
\hline $\mathrm{CPF}$ measured by a spirometer, mean $\pm \mathrm{SD} \mathrm{L} / \mathrm{min}$ & $54 \pm 30$ & $86 \pm 37$ & $<.001$ \\
\hline $\mathrm{CPF}$ measured by a ventilator, mean $\pm \mathrm{SD} \mathrm{L} / \mathrm{min}$ & $50 \pm 22$ & $80 \pm 26$ & $<.001$ \\
\hline
\end{tabular}


Table 2. Outcomes Between Subjects With and Without Re-intubation

\begin{tabular}{|c|c|c|c|}
\hline Outcomes & Re-Intubation $(n=15,12 \%)$ & No Re-Intubation ( $n=111,88 \%)$ & $P$ \\
\hline Hospital stay, median (IQR) d & $19(12-25)$ & $17(11-24)$ & .34 \\
\hline ICU stay, mean $\pm \mathrm{d}$ & $16 \pm 9$ & $11 \pm 9$ & .046 \\
\hline Postextubation hospital stay, median (IQR) d & $4(2-10)$ & $9(5-16)$ & .063 \\
\hline Postextubation ICU stay, median (IQR) d & $4(1-10)$ & $4(1-7)$ & .62 \\
\hline Hospital mortality, $n(\%)$ & $12(80)$ & $9(8)$ & $<.001$ \\
\hline
\end{tabular}

$\overline{\mathrm{QQR}}=$ interquartile range

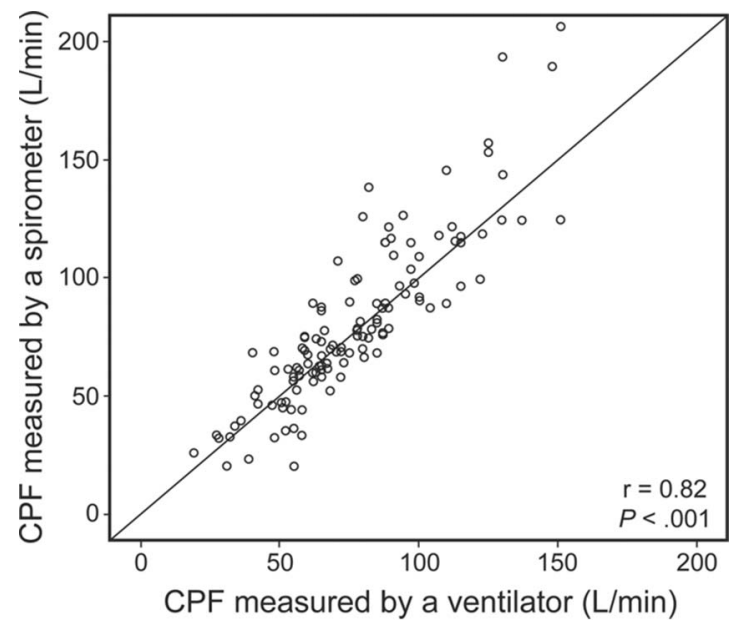

Fig. 3. Correlation between cough peak flow (CPF) measured by a ventilator and a spirometer.

operating characteristic was similar between CPF measured by a spirometer and a ventilator $(P=.26)$ (Fig. 4).

\section{Discussion}

The current study shows that CPF had high sensitivity and specificity to predict re-intubation in subjects with planned extubation. It could be measured by a spirometer or a ventilator. CPF measured by a spirometer was slightly higher than that measured by a ventilator. However, the 2 methods had similar predictive accuracy for re-intubation. Further, measuring CPF with a ventilator did not lead to any additional costs.

Previous studies have demonstrated that cough strength is strongly associated with re-intubation.5,9-20 Our study also confirmed this relationship. However, our research differed from previous studies, since we used 2 methods to assess cough strength (a spirometer and a ventilator), and found the 2 methods had similar predictive accuracy for re-intubation. It provided more choices for caregivers when they assessed the cough strength.

Cough strength can be assessed by a semiquantitative measurement. The method we usually used was a scale rated by the caregivers as follows: $0=$ no cough on com- mand, $1=$ audible movement of air through the endotracheal tube but no audible cough, 2 = weakly (barely) audible cough, $3=$ clearly audible cough, $4=$ stronger cough, and $5=$ multiple sequential strong coughs. ${ }^{12} \mathrm{~Pa}-$ tients with a score of $\leq 2$ were classified as having a weak cough. However, semiquantitative measurement of cough strength was mainly based on the experience of the caregivers. Different caregivers, especially inexperienced ones, may grade differently when they rate the same patient. Thus, semiquantitative measurement of cough strength is not accurate.

Cough strength also can be assessed by a quantitative measurement. We usually used a flow meter to measure $\mathrm{CPF}$. To the best of our knowledge, 3 studies have found that the optimal cutoff value of CPF was $60 \mathrm{~L} / \mathrm{min} .{ }^{16,17,20} \mathrm{An}$ other study found that the optimal cutoff value was 58.5 L/min. ${ }^{19}$ In the current study, we found that the optimal cutoff values were 56.4 and $56 \mathrm{~L} / \mathrm{min}$ when measured by a spirometer and a ventilator, respectively. The values were very close to those identified in previous studies, which indicates that CPF has good repeatability. Thus, the quantitative measurement of cough strength may be more accurate than semiquantitative measurement.

Quantitative measurement of cough strength required a flow meter. To the best of our knowledge, all of the studies used an additional flow meter and a bacterial filter to quantitatively measure cough strength. ${ }^{14-20}$ Before measurement, the ventilator was disconnected. It interrupted ventilation and oxygen delivery. This may result in hypoventilation and hypoxemia. Further, the risk for hospital infection may increase when the ventilator is disconnected and the patient coughs, especially in patients with respiratory infectious disease, such as tuberculosis. Moreover, the additional flow meter and bacterial filter add cost, although the cost is not high. In addition, not all ICUs provide an additional flow meter to measure cough strength. However, a ventilator is available in all ICUs, and they include an internal flow meter. This internal flow meter can be used to measure flow velocity. In our study, we used the internal flow meter of the ventilator to measure $\mathrm{CPF}$ and found that it had the same predictive accuracy for re-intubation as an additional flow meter. Thus, CPF mea- 
Table 3. Analysis of Cough Peak Flow by Receiver Operating Characteristic Curves

\begin{tabular}{|c|c|c|c|c|c|c|c|c|}
\hline CPF Measured by & $\begin{array}{l}\text { Optimal Cutoff } \\
\text { Value (L/min) }\end{array}$ & SE $(\%)$ & $\mathrm{SP}(\%)$ & $\begin{array}{c}\text { AUC } \\
(95 \% \mathrm{CI})\end{array}$ & $\begin{array}{c}\text { Positive } \\
\text { Predictive } \\
\text { Value }(\%)\end{array}$ & $\begin{array}{l}\text { Negative } \\
\text { Predictive } \\
\text { Value }(\%)\end{array}$ & $\begin{array}{l}\text { Positive } \\
\text { Likelihood } \\
\text { Ratio }\end{array}$ & $\begin{array}{c}\text { Negative } \\
\text { Likelihood } \\
\text { Ratio }\end{array}$ \\
\hline Spirometer & 56.4 & 73 & 87 & $0.79(0.71-0.86)$ & 42.3 & 96.0 & 5.43 & 0.31 \\
\hline Ventilator & 56.0 & 73 & 85 & $0.83(0.75-0.89)$ & 39.3 & 95.9 & 4.79 & 0.31 \\
\hline $\begin{array}{l}\mathrm{CPF}=\text { cough peak flow } \\
\mathrm{SE}=\text { sensitivity } \\
\mathrm{SP}=\text { specificity } \\
\mathrm{AUC}=\text { area under the cur }\end{array}$ & & & & & & & & \\
\hline
\end{tabular}

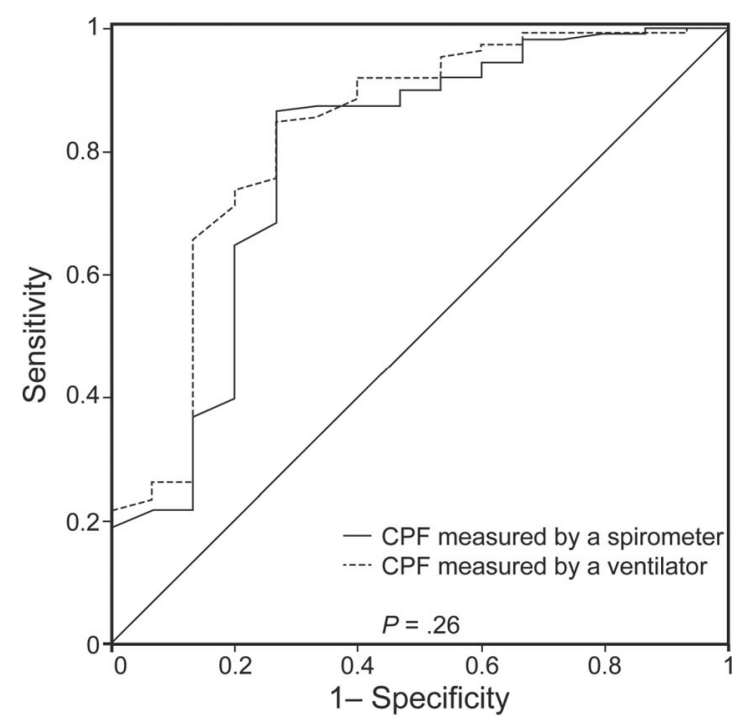

Fig. 4. Predictive accuracy of re-intubation diagnosed by cough peak flow (CPF) when it was measured by a spirometer and a ventilator.

sured by a ventilator is a good method to assess cough strength.

We found that CPF measured by a ventilator was slightly lower than that measured by a spirometer. It is possible that the difference resulted from transducer placement. The transducer was placed at the end of the endotracheal tube when CPF was measured by a spirometer. However, the flow meter is at the inside of the ventilator, with the flow signal transmitted through the ventilator circuit. Usually, the length of the ventilator circuit is $1-2 \mathrm{~m}$. Thus, a long circuit may result in attenuation of the flow signal and subsequently result in a lower CPF measured by a ventilator than that measured by a spirometer.

Our study has several limitations. First, CPF was read from the graph of the ventilator when we coached the subject to cough (Fig. 1). However, some ventilators do not include the function of graph display. So, these types of ventilators cannot be used to measure CPF. Second, the length of the circuit differs between different ventilators. A longer length of ventilator circuit may lead to more attenuation of the flow signal and produce a lower CPF. However, we did not investigate the association between the length of the ventilator circuit and the attenuation of the flow signal. Thus, this issue needs further exploration. Third, this is a single-center study with a small sample size. The confirmation of predictive accuracy for re-intubation diagnosed by CPF measured by a ventilator is encouraged at other centers using a larger sample size. Fourth, weak cough is only one risk factor for re-intubation. Other risk factors include advanced age and prolonged mechanical ventilation preceding extubation. ${ }^{22,23}$ Thus, the decision of extubation should reference not only cough strength, but also other risk factors, such as age and duration of mechanical ventilation.

\section{Conclusions}

CPF measured by a ventilator had a predictive accuracy for re-intubation similar to that of a spirometer. Because this measurement has no additional cost and ventilators are present in all ICUs, it can be widely used to measure cough strength in planned extubation patients.

\section{REFERENCES}

1. MacIntyre NR, Cook DJ, Ely EW Jr, Epstein SK, Fink JB, Heffner $\mathrm{JE}$, et al. Evidence-based guidelines for weaning and discontinuing ventilatory support: a collective task force facilitated by the American College of Chest Physicians; the American Association for Respiratory Care; and the American College of Critical Care Medicine. Chest 2001;120(6 Suppl):375S-395S.

2. Boles JM, Bion J, Connors A, Herridge M, Marsh B, Melot C, et al. Weaning from mechanical ventilation. Eur Respir J 2007;29(5): 10331056.

3. Macintyre NR. Evidence-based assessments in the ventilator discontinuation process. Respir Care 2012;57(10):1611-1618.

4. Pu L, Zhu B, Jiang L, Du B, Zhu X, Li A, et al. Weaning critically ill patients from mechanical ventilation: a prospective cohort study. J Crit Care 2015;30(4):862.e7-e13.

5. Thille AW, Boissier F, Ben Ghezala H, Razazi K, Mekontso-Dessap A, Brun-Buisson C. Risk factors for and prediction by caregivers of extubation failure in ICU patients: a prospective study. Crit Care Med 2015;43(3):613-620. 


\section{Cough Peak Flow Measured by a Ventilator}

6. Solsona JF, Díaz Y, Vázquez A, Pilar Gracia M, Zapatero A, Marrugat J. A pilot study of a new test to predict extubation failure. Crit Care 2009;13(2):R56.

7. Huang CT, Tsai YJ, Lin JW, Ruan SY, Wu HD, Yu CJ. Application of heart-rate variability in patients undergoing weaning from mechanical ventilation. Crit Care 2014;18(1):R21.

8. Gao F, Yang LH, He HR, Ma XC, Lu J, Zhai YJ, et al. The effect of reintubation on ventilator-associated pneumonia and mortality among mechanically ventilated patients with intubation: a systematic review and meta-analysis. Heart Lung 2016;45(4):363-371.

9. Duan J, Zhou L, Xiao M, Liu J, Yang X, et al. Semiquantitative cough strength score for predicting reintubation after planned extubation. Am J Crit Care 2015;24(6):e86-e90.

10. Nantsupawat N, Nantsupawat T, Limsuwat C, Sutamtewagul G, Nugent $\mathrm{K}$. Factors associated with reintubation in patients with chronic obstructive pulmonary disease. Qual Manag Health Care 2015;24(4):200-206.

11. Anderson CD, Bartscher JF, Scripko PD, Biffi A, Chase D, Guanci M, Greer DM. Neurologic examination and extubation outcome in the neurocritical care unit. Neurocrit Care 2011;15(3):490-497.

12. Khamiees M, Raju P, DeGirolamo A, Amoateng-Adjepong Y, Manthous CA. Predictors of extubation outcome in patients who have successfully completed a spontaneous breathing trial. Chest 2001; 120(4):1262-1270.

13. Huang CT, Yu CJ. Conventional weaning parameters do not predict extubation outcome in intubated subjects requiring prolonged mechanical ventilation. Respir Care 2013;58(8):1307-1314.

14. Kutchak FM, Debesaitys AM, Rieder Mde M, Meneguzzi C, Skueresky AS, Forgiarini Junior LA, Bianchin MM. Reflex cough PEF as a predictor of successful extubation in neurological patients. J Bras Pneumol 2015;41(4):358-364.
15. Duan J, Liu J, Xiao M, Yang X, Wu J, Zhou L. Voluntary is better than involuntary cough peak flow for predicting re-intubation after scheduled extubation in cooperative subjects. Respir Care 2014; 59(11):1643-1651.

16. Smailes ST, McVicar AJ, Martin R. Cough strength, secretions and extubation outcome in burn patients who have passed a spontaneous breathing trial. Burns 2013;39(2):236-242.

17. Salam A, Tilluckdharry L, Amoateng-Adjepong Y, Manthous CA. Neurologic status, cough, secretions and extubation outcomes. Intensive Care Med 2004;30(7):1334-1339.

18. Beuret P, Roux C, Auclair A, Nourdine K, Kaaki M, Carton MJ. Interest of an objective evaluation of cough during weaning from mechanical ventilation. Intensive Care Med 2009;35(6):1090-1093.

19. Su WL, Chen YH, Chen CW, Yang SH, Su CL, Perng WC, et al. Involuntary cough strength and extubation outcomes for patients in an ICU. Chest 2010;137(4):777-782.

20. Smina M, Salam A, Khamiees M, Gada P, Amoateng-Adjepong Y, Manthous CA. Cough peak flows and extubation outcomes. Chest 2003;124(1):262-268.

21. Hanley JA, McNeil BJ. A method of comparing the areas under receiver operating characteristic curves derived from the same cases. Radiology 1983;148(3):839-843

22. Thille AW, Harrois A, Schortgen F, Brun-Buisson C, Brochard L. Outcomes of extubation failure in medical intensive care unit patients. Crit Care Med 2011;39(12):2612-8.

23. Thille AW, Boissier F, Ben Ghezala H, Razazi K, Mekontso-Dessap A, Brun-Buisson C. Risk factors for and prediction by caregivers of extubation failure in ICU patients: a prospective study. Crit Care Med 2015;43(3):613-620. 